\title{
Understanding the Journey Through Homelessness: A Hermeneutic Study of Women Without Children
}

\author{
Joseph C. Osuji \\ Mount Royal University \\ Sandra P. Hirst \\ University of Calgary
}

\begin{abstract}
This study explored the meaning of the experience of homelessness and exiting homelessness among women without children. Convenience and snowball sampling techniques were used to recruit 12 women in an urban centre in Canada. Texts resulting from audiotaped interviews, participant observations, and reflective journal entries constituted data for analysis. Gadamerian hermeneutics informed the interpretive method used for analysis. The analysis yielded 5 subthemes that described the journey: (a) loss of self at home: the trigger; (b) non-feeling of "at-homeness": dissociation; (c) disconnection and aloneness: homelessness; (d) simulating home: transitional shelter living; and (e) finding oneself: hopefulness. Findings suggest that exiting homelessness for women was a journey in search of hope, and reconnection with the self and others. This perspective suggests a new approach for policy and practice.
\end{abstract}

Keywords: home, homelessness, hermeneutics, women

\section{RÉSUMÉ}

Dans cette étude, nous explorons la signification que des femmes sans enfants donnent au fait de vivre l'itinérance et d'en sortir. Nous avons recruté 12 femmes dans une grande ville canadienne grâce à la technique du sondage en boule de neige. Les interviews que nous avons menées avec elles, leurs observations et un journal de bord ont servi de matière à notre interprétation et à notre analyse, fondées sur l'herméneutique de Gadamer. Nous avons ainsi établi 5 sous-thèmes qui décrivent le parcours de ces femmes : (a) perte de l'identité à la maison : le déclencheur; (b) sentiment de ne pas avoir de chez-soi : la dissociation; (c) « déconnexion » et isolement : l'itinérance; (d) « simulation » d'un chez-soi : la vie en refuge pour itinérantes;

Joseph C. Osuji, Mount Royal University; Sandra P. Hirst, Faculty of Nursing, University of Calgary.

Correspondence concerning this article should be addressed to Joseph C. Osuji, Mount Royal University, 4825 Richard Road SW, Calgary, AB T3E 6K6. Email: josuji@mtroyal.ca 
(e) « redécouverte » de l'identité : l'espoir. Notre analyse indique que les efforts de ces femmes pour sortir de l'itinérance ont constitué un parcours qu'elles ont fait à la recherche d'espoir, pour se « reconnecter » avec elles-mêmes et avec les autres. Cette façon de concevoir ce phénomène pourrait suggérer une nouvelle approche en matière de politiques publiques et de la pratique des divers intervenants et intervenantes.

Mots clés : chez-soi, itinérance, herméneutique, femmes

Homelessness has come to the forefront of social ills plaguing societies across the globe, and how best to deal with this and reduce the number of those who are experiencing homelessness is an ongoing debate among policy makers and social scientists. It is obvious that the number of people experiencing homelessness is increasing, their average age is dropping, and more women and family units are becoming part of this population (Coates \& Mckenzie-Mohr, 2012; Makiwane, Tamasane, \& Schneider, 2010; Ploeg, Hayward, Woodward, \& Johnston, 2008; Rogers \& Marshall, 2012). Individuals experiencing homelessness are by definition isolated from mainstream society; they lack stable housing and often have lost connections with jobs, families, and communities (Cronley, 2010). People without homes are often referred to as just "the homeless," but a closer look at the phenomenon reveals that experiencing homelessness means more than just having no fixed address; it also means disengagement from society, from community, and from one's support system.

There have been very few studies focusing on the experiences of women who do not have children with them while living on the streets. Other studies focusing on families or women with children experiencing homelessness do not necessarily address the needs and characteristics of those without children, since the defining variable most times is the presence of children. The presence of children in these circumstances may be a very important variable in determining what needs exist, what support may be available to these women, and how soon they can transition out of homelessness (Ruttan, Laboucan-Benson, \& Munro, 2012).

\section{LITERATURE REVIEW}

Although it is challenging to accurately determine the numbers of people who are actually homeless (Richter \& Chaw-Kant, 2010), most researchers agree that there has been a significant growth in the numbers of individuals experiencing homelessness and accessing emergency shelters. In Canada, it is estimated that between 150,000 and 300,000 individuals are experiencing homelessness (Graham \& Schiff, 2010). The city of Calgary has counted the numbers of homeless people within the city since 1992. According to the Calgary Homeless Foundation (2011), the city's homeless population has grown from 447 individuals in 1992 to 4,060 in 2008, representing a 900\% increase in their numbers. Studies conducted in other Canadian urban centres indicate a similar trend (Shephard, Low, \& Meisner, 2003; Woodward, Eberle, \& Kraus, 2002).

Breaking these numbers down according to gender, however, is problematic. Few Canadian cities have attempted to count the numbers of women living on the streets at particular times. The National Working Group on Women and Housing (2006) reported that in the 2006 Toronto street count, women made up 26\% of the homeless population. In Calgary, $24 \%$ of the observed homeless population was made up of women in 2012 (Calgary Homeless Foundation, 2012). 
Demographically, there is no homogenous face to homelessness. This population consists of men, women, children, and family units who rely on emergency shelters for food and housing, simply sleep out in the cold, in cars, train stations, or sometimes double up with relations or friends. Bahr and Caplan (1974) used the disaffiliation framework to examine the phenomena of homelessness and homelessness trajectories. Disaffiliation, according to Bahr and Caplan, refers to "systematic detachment from society of people who become homeless" (p. 56). The disaffiliated see society as withdrawing from them, and they see themselves as strangers after they lose affiliative bonds with family, friends, and society. Three stages lead to disaffiliation in this framework: external changes that result in inadequate social support, individual estrangement from society, and a life of isolation. For the purposes of this inquiry, the disaffiliation framework provided a structure for exploring the meanings of home and homelessness, and the understanding of the experience of homelessness among women without children.

Grigsby, Baumann, Gregorich, and Roberts-Gray (1990) applied the disaffiliation framework to describe a social process model of entrenchment in homelessness and argued it was more likely for individuals experiencing homelessness for the first time to proceed to chronic homelessness rather than to reconnect with society. They found that the recently homeless were more likely to cope with their circumstances by affiliating with others who were permanently homeless, instead of "re-connecting with friends and family" (p. 142).

Women are becoming a larger proportion of the homeless population and are considered most vulnerable. Studies have shown that the rates of mortality and morbidity among homeless women under 45 years old are greater than all other sections of society (Hwang, 2002). Jackson-Wilson and Borgers (1993) suggested that homelessness among women "appears to be associated with the dissociation that results from family instability in childhood, abuse in families of origin, and mental health difficulties" (p. 362). Dissociation means an absence of affiliative bonds that would connect the homeless to supportive social networks. Other antecedent factors to homelessness among women include "eviction, mental health and addiction issues, domestic violence and abuse, and other family problems" (Miller \& DuMont, 2000, p. 116). Therefore many women experiencing homelessness find that their entire social support network has dissolved.

Milburn and D'Ercole (1991) suggested that homelessness is a stressor that in itself makes exiting the condition of homelessness "extremely difficult (p. 1163). Women's experience of homelessness is compounded by other stressors such as poverty, housing instability, problems with employment, and self-victimization.

Among women, absolute homelessness seems to be a crisis that typically occurs in conjunction with the exhaustion and collapse of social networks. Social networks provide a sense of identity and self-esteem among women (Fry \& Barker, 2002; Nyamathi, 2008). When social networks collapse, the state of homelessness, especially among women without children, tends to become self-perpetuating. Toohey, Shinn, and Weitzman (2004) suggested that homeless women without children are the hidden homeless because they are predisposed to use up their social networks by relying overly on "friends and family for support, and a sofa for the night, only to be kicked out when they have eventually worn out their welcome" (p. 7) and thus end up on the streets as a last resort.

The relative silence in published literature of the voice of women without children experiencing homelessness may have much to do with the fact that these women seem to be "out of sight" rather than visible on the streets. Women are more inclined to "double up" with family and friends, for as long as possible, when they find themselves in "situations that predispose them to homelessness" (Evans \& Forsyth, 2004, p. 483). 
This social invisibility, according to Evans and Forsyth (2004), may also be a consequence of "the nearly exclusive access of women to battered women's shelters, [which] results in an underestimation of women in studies that employ traditional definitions of homelessness" as lack of home address (p. 485).

This general inclination by women experiencing homelessness to remain out of public view may have a lot to do with the societal expectation for women to remain at home and in the background, and the inherent dangers faced by these women when they become homeless. Research has shown that single women who are homeless are more likely to experience "involuntary sex, physical or sexual abuse and ... feelings of fear and insecurity" (Millburn, Rotheran-Borus, Rice, Mallet, \& Rosenthal, 2006, p. 67). Therefore in order to remain safe and maintain some semblance of self-respect, these women go through great lengths to be invisible to the public when they become homeless - a behaviour that compounds the difficulties they experience as a result of homelessness.

There have been numerous studies on the determinants of homelessness in women or their pathways into homelessness (Gamache, Rosenheck, \& Tessler, 2003; Lenon, 2000; Metraux \& Culhane, 1999; Miller \& DuMont, 2000; Olufemi, 2000; Tischler \& Vostanis, 2007), but none have focused on the exit experience from homelessness, especially for women without children. This obvious gap in the literature underscores the impetus for this study. Understanding the experience of reaffiliation and the meanings attributed to this experience may be the starting point in caring for women without children experiencing homelessness or at risk of becoming homeless. It is likely that understanding this experience among women will enhance the design and delivery of programs to assist them to exit homelessness.

This study contributes to the literature on homelessness by exploring the meaning of the lived experience of homelessness and exit from homelessness among women without children. The intention was to understand the personal meanings attributed to this experience by these women as they dealt with and worked to exit homelessness, beyond the obvious interpretations by the society as a journey in search of home.

\section{RESEARCH METHOD}

The overall design for this research study is qualitative, approached specifically through a hermeneutic phenomenological perspective that is rooted in Gadamerian philosophical hermeneutics (Gadamer, 2004). A hermeneutic phenomenological study seeks to interpret research participants' retrospective reflections on their lived experiences and to "give voice to human experience just as it is" (Jardine, 1990, p. 222). Hermeneutic phenomenology offers enough freedom to give voice to such a complex interactional phenomenon as the experience of homelessness and exit from it, because this approach to research honours the place of context and historicity in such a topic. The interpretive process in hermeneutic phenomenology therefore seeks to bring understanding and disclosure to phenomena through language.

\section{Research Site and Recruitment Strategy}

A large urban centre (Calgary) was used, because it has facilities dedicated to the service of those experiencing homelessness. Research participants were recruited on a strictly voluntary basis, through purposeful sampling, complemented with convenient and snowball sampling techniques. This combination of techniques ensured the participation of information-rich individuals able to provide insiders' perspectives 
on the experience being studied. Twelve women who lived in a transitional shelter and had no children with them were interviewed. The transitional shelter is designed to provide temporary residential spaces for women and their families who are experiencing homelessness, until they are able to secure more permanent housing. These shelters provide accommodation for a period of time ranging from weeks to months, provided that residents agree to abide by certain rules that govern shelter living. These rules include, among others, observing curfews, staying drug and alcohol free, participating in shelter programs such as counselling, work training, and workshops, maintaining formal regular contacts with assigned staff at the shelter, and active house hunting with assistance from shelter staff.

\section{Demographics}

The ages of participants ranged from 36 to 65 , with an average age of 44.2 years. Their formal education ranged from grade school to college degrees. Their average stay at the transitional shelter was 3.6 months at the time of the interview. Ninety-two percent of participants reported some form of mental illness and or addiction problems, $75 \%$ had been previously married, and $50 \%$ had jobs at the time of the interview. The majority of participants (83\%) were Caucasians, while 17\% were of First Nations' descent. Sixteen percent of participants were experiencing homelessness for the first time. All study participants had experienced some form of abuse in their past; $75 \%$ had experienced child abuse, while $58 \%$ had experienced spousal abuse that was related to their homelessness experience. Nine participants had children who were staying elsewhere.

\section{Sources of Data}

Face-to-face unstructured interviews with participants, combined with participant observations and reflective notes by the researchers, were the major data collection strategies. Open-ended interview questions were used to engage in genuine conversation with participants. Interviews and observations lasted 45-90 minutes, and were taped and transcribed verbatim. Sample interview leading questions included, "Tell me about your homelessness experience. How did you get to become homeless? Tell me what it means to you to be exiting homelessness." Open-ended questions like "Tell me more about that" or "Can you expand on that?" were used to encourage participants to expand on their responses.

Participant observation occurred during interviews. The incorporation of observation with interviews was based on the premise that "interview data are more than verbal records and should include as much as possible, non-verbal features of the interaction" (Fontana \& Frey, 2000, p. 661). The researchers observed non-verbal cues, facial expressions, emotions, body language, and gestures of participants. Throughout the research process, field notes offered a medium to capture events that were of interest, insights and challenges, or new impressions of participants and their stories.

\section{Ethics}

Ethics approval was obtained from the university. During the informed consent process, participants were adequately informed about what their involvement would entail, potential risks and benefits, and their rights to withdraw at any point during the study. To protect participants' confidentiality, interviews were conducted on an individual basis and real names were not identified in written documents. 


\section{The Interpretation of Data}

Meaning in hermeneutics emerges as the text and the interpreter engage in a dialogue, in a metaphorical circular fashion referred to as the hermeneutic circle. According to Moules (2002), the "hermeneutic circle is not a method for uncovering meaning, but a metaphorical way of conceptualizing understanding and the process of interpretation of which [the researcher] participates, belongs [to] and [is] situated" (p. 30). Interpretation began with an introspective exercise aimed at identifying and understanding our own biases, assumptions, and prejudices. Data were analyzed in an interpretive manner consistent with philosophical hermeneutics (Fleming, Gaidys, \& Robb, 2003), with recognition of reflexivity throughout the process. Reflexivity is described by Fleming et al. (2003) as "thoughtful, conscious self-awareness" (p. 36) in which researchers take into account their own assumptions and biases in analyzing data. We recognized that we could not be placed outside the questions we had set out to explore in this study. A clearer understanding and interpretation of the phenomenon and experience in question was made possible for us by exploring own biases and prejudices about homelessness.

The cyclic nature of questioning and verifying data with colleagues and research participants during the data collection and analysis guided our initial concepts and developing understandings; these were modified as more data were collected and analyzed. By reading and rereading the transcripts and field notes, moving from words, to sentences or paragraphs, to the whole document and back again in an ongoing process of interpretation, the researchers were able to construct new understandings about the experience of homelessness among participants.

According to Cohen, Khan, and Steeves (2000), hermeneutic phenomenological data analysis is aimed at providing a "thick and rich description of a meaningful text that captures and communicates the meaning of the lived experience being explored" (p. 47). Data analysis began with interviews and the collection of other research data. Analysis progressed with the formulation of vague and tentative notions about the meanings of the experience of homelessness and exit from homelessness as narrated by interviewees. This process signified our engagement in the hermeneutic circle, which according to Cohen et al. suggests a "continuous dialectic analysis of interview data, considering the meanings of the smallest units of data in terms of ever-increasing larger units of data, and vice versa" (p. 73). We read and reread the data collected during the interviews and explored the meanings behind the vocalized words, silences, and body language of participants.

Data analysis for this study was conducted according to the three steps proposed for use in hermeneutic phenomenology by Streubert-Speziale and Rinaldi-Carpenter (2007). These steps include (a) naïve reading of the text, (b) structural analysis or interpretive reading, and (c) interpretation of the whole. Though the description of these steps may appear inevitably lineal, it is important to note that in reality, data analysis in hermeneutic phenomenology is neither methodical nor lineal, nor does it adhere to a step-by-step process (Cohen et al., 2000). As we progressed in the data analysis, we found reasons to revisit the interview transcripts, go back to the data already analyzed, and scrutinize new and emerging meanings against previous understandings.

During the naïve reading stage, the researcher "reads the text as a whole to become familiar with the text, and begins to formulate thoughts about its meaning for further analysis" (Streubert-Speziale \& 
Rinaldi-Carpenter, 2007, p. 89). Analytic tasks that occurred during this stage included transcription of data and data organization, preliminary interpretation of data, and beginning understandings of the meaning of data.

Structural analysis or interpretive reading involves "identifying patterns of meaningful connections" (Streubert-Speziale \& Rinaldi-Carpenter, 2007, p. 89) in the data, which culminates in the identification of themes. We engaged deeply with the data, through reading and rereading the interview transcripts, to identify and explore emerging themes. This culminated in the writing and rewriting of a descriptive and interpretive text on the essential themes identified. It was during this phase that we scrutinized and edited the interview and observational data to remove identifiers and statements that seemed to be digressions or unimportant, being careful not to change the unique characteristics of each interview.

Interpretation of the whole data involved reflection on the initial reading, along with interpretive reading to ensure a comprehensive understanding of the findings (Streubert-Speziale \& Rinaldi-Carpenter, 2007, p. 89). In a hermeneutic phenomenological interpretation, no attempt is made to become reductionistic or generalisitic; instead, as Munhall (2001) described it, "there is a moving away from the idea of synthesizing experience into one narrative fits all" (p. 175). The aim was for heterogeneity of meaning, which resulted from the differing perspectives or contexts in which the phenomenon was experienced by research participants. During this phase, we continued to identify and connect themes, link literature to these themes, and construct an interpretation of the data according to the circular nature of the hermeneutic cycle. This led to the simultaneous examination of narratives within the emerging interpretation without losing sight of each participant's unique story, context, and experience (Crist \& Tanner, 2003, p. 203).

\section{FINDINGS}

An overall theme that emerged from participant interviews was that experiencing homelessness and working to exit this condition among women represented a journey through losing oneself, self-discovery, and hope. Participants described their experiences of living on the streets as an inevitable and a consequential journey - not a choice but a consequence of their initial decision to leave unacceptable living circumstances at home. This journey through homelessness was a difficult one that actually started while they still lived in their homes. They left home to embark on this journey in order to escape the homelessness they felt.

Five themes emerged from dwelling in a hermeneutic cycle with the interview texts:

1. Loss of self at home: The trigger

2. Non-feeling of "at-homeness": Detachment

3. Disconnection and aloneness: Homelessness

4. Simulating home: Transitional shelter living

5. Finding oneself: Hopefulness

This journey through homelessness is represented in Figure 1. 


\section{Figure 1}

Visual Representation of Participants' Journeys Through Homelessness

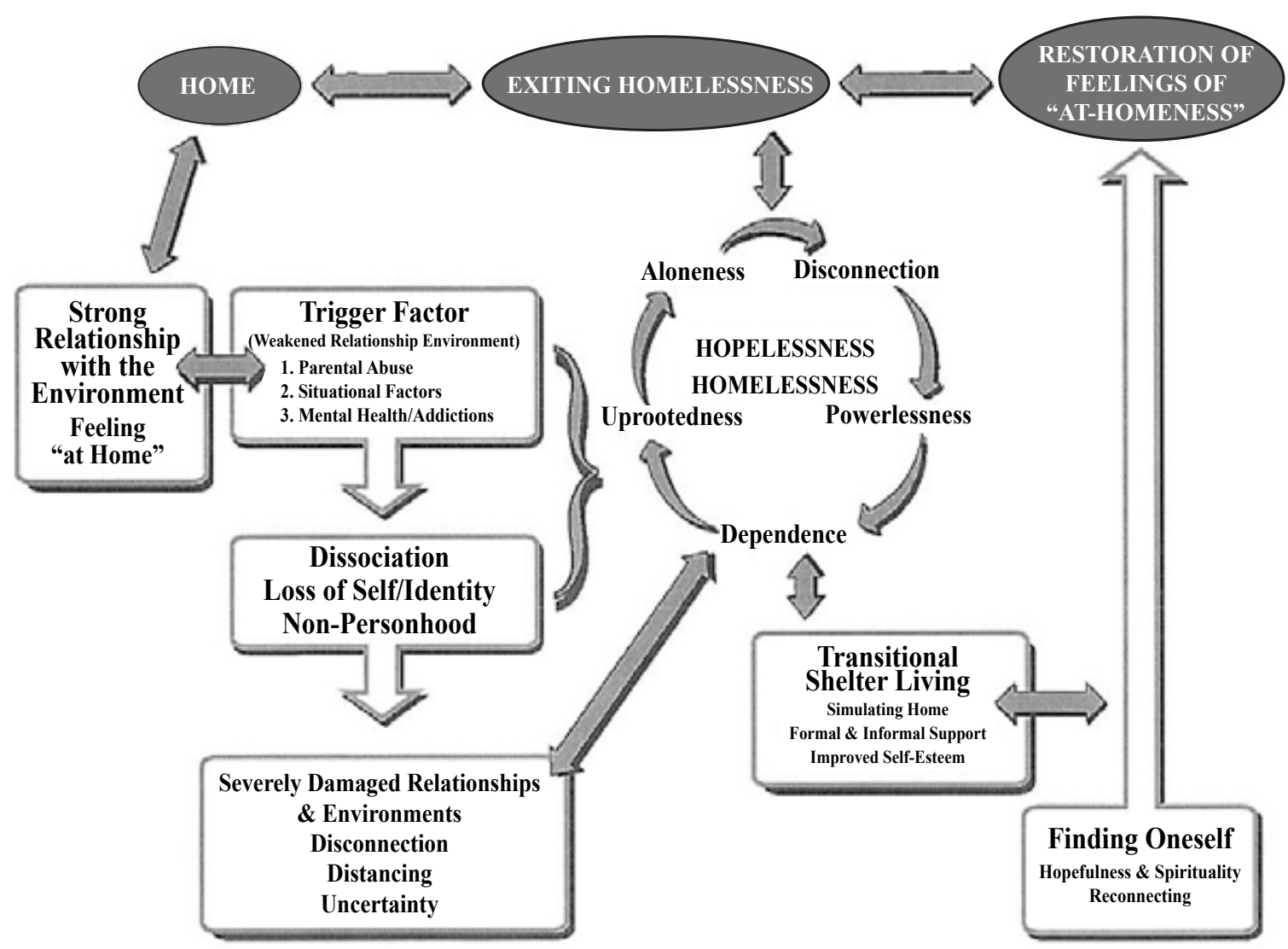

\section{Loss of self at home: The trigger}

Being homeless means losing yourself and finding a home means rediscovering yourself. Nobody decides to be homeless. I am homeless because I am an addict, but I do drugs to numb my pain, to escape the pain of loss, homelessness, hopelessness, and depression. I got lost at home because of circumstances beyond my control [deep frown, no eye contact]. - Maria

Participants talked about a trigger to their feelings of homelessness at home and their subsequent journeys in search of a better home. These were specific occurrences at home that defeated their sense of being at home. Most triggers were related to negative home situations that compounded existing mental health concerns. The women escaped when they felt their lives endangered. Lana described her ideal home as a "place where one is loved, where you are cared for, and where there is laughter." To feel at home according to her meant "being happy, being loved, being content, and being cared for in your environment." Cara stated that she never felt that she had a home because she was abused there. She could no longer trust others, and 
she struggled with all adult relationships. In response to these trigger factors at home, participants had lost the feeling of at-homeness. They had lost hope in themselves and in others. They felt depersonalized and helpless.

\section{Non-feeling of "at-homeness": Detachment}

For me I never really had a home, I had only a house and never felt at home. That made me run away from home looking for a better place to call home; home is where the heart is [sobbing]. - Tara

Participants voiced that their living circumstances at home did not live up to their expectations of a home. This disconnect resulted in the loss of the feeling of at-homeness and confusion about their personal identities. Karen felt that home should be a place where she "could just sit back, stay put, and feel secure." According to her, "to feel at home does not mean to have a house." Her words were echoed in those of other participants. Tara spoke about how she felt homeless even while she lived at home, a feeling that robbed her of her sense of belonging and self-esteem. She felt lost and disconnected from herself and others. The loss these women experienced at home affected their feelings toward themselves and their personal identities, resulting in detachment and loneliness.

\section{Disconnection and aloneness: Homelessness}

It's the loneliness! It's the lack of connection to myself and to home, now I mean real home. You are alone ...

It is the loneliness that creeps up on you and just debilitates you. - Karen

The terms "alone," "lonely," and "disconnected" from self and others were frequently used by participants to describe their homelessness experiences. Cara mentioned that this period of her journey in search of home was marked by detachment: "Even if I had 50 people around me, I still felt alone, because I was so detached from the world."

Participants alluded to many other ways women could become homeless without losing their dwellings, such as staying put in an abusive relationship, having children trapped in abusive families, and having mental illnesses or addictions that go untreated. Though experiences of loneliness started when these women were still at home, their loneliness deepened when they left home and lived on the streets. They variously described this experience of homelessness as "shameful," "let down on oneself," "horrible," and "debilitating." Experiences of avoidance and self-exclusion occurred as the women attempted to limit the negative responses from others toward their homeless state. Brenda said, "It seemed that the whole world has totally stopped and let you off. You are on your own." Experiences of loneliness interfered with the ability of some participants to make sound personal decisions and encouraged destructive coping behaviours, such as drug use and excessive drinking. Shirley described this period:

It's a lot of negative behaviour, a lot because you are angry and lost. Being a woman on the streets, you have to look like you're a bitch out there to survive. You have to fit in to survive, because if you look wimpy, they are going to chew you up. That's why we turn to drugs and alcohol [smiling].

\section{Simulating home: Transitional shelter living}

Here, you make a goal and follow through. On the streets you make goals and they are made to be broken. Here they give you time, you have group or individual counselling. It's like a different kind of home here, people support you. It's like belonging to a big family. It gives me hope [arms to her chest]. —Elaine 
Although participants described home mostly in terms of relationships and the feelings of at-homeness, they did not discount the importance of the temporary space they could call "home," especially when such a space gave them the opportunity to rebuild hope. Elaine admitted that her decision to live at the shelter was the beginning of her real progress to exit homelessness, because it made her feel accepted and renewed her hope in life. Living at the transitional shelter reduced the loneliness she felt, and enabled her to think "more clearly" and focus on her personal journey to exit homelessness. For all participants, living at the transitional shelter represented the beginning of a restored feeling of at-homeness, enhanced their self-efficacy, and gave them access to other services that assisted them in dealing with issues such as addictions and mental health care. Heather added that she would have left the homeless situation a long time ago if she had moved into a place like the transitional shelter right after she escaped her last abusive husband.

Participants commented that women should not be allowed to be homeless and that a physical structure to move into as soon as they lose their homes would support their journeys out of homelessness. According to Cara, "A woman needs a house or at least somewhere to stay in order to improve her chances of succeeding in this process of reconnection with the self and the society."

\section{Finding oneself: Hopefulness}

It is the love that other people had for me when I could not love myself. They kept letting me know that I was worth more and didn't give up on me even after I had given up on myself... That's what is keeping me going. - Cara

Cara identified counselling sessions available to her, assistance from others, and group activities as being instrumental to helping her stay sober and think clearly. Elaine also spoke about the benefits of participating in group activities:

Groups are good because I felt I wasn't the only person feeling like this and I wasn't the only one who was beaten, or had a home before and lost it, or lost a child, that I wasn't a lonely sufferer. It's like a big family here. It increases the amount of support you can have from others, [and] that gives me hope.

Participants admitted that being sober as required by the shelter allowed them to think clearly and be honest with themselves. According to Maria, "The only way out of homelessness is [being] honest with yourself, realizing that you may have a lot to do with your homelessness situation." She underscored how difficult this realization could be for women who were still on the streets or stuck in abusive relationships:

But sometimes being honest with yourself is painful, making amends is painful, but being sober brings you to realization ... not having to numb that pain is the only thing that is allowing me to move forward. You cannot do this if you are still on the streets or ... not willing to leave that abusive relationship, without being sober. You are stuck in the cycle.

\section{DISCUSSION}

\section{Exiting Homelessness Is a Journey Through Losing Oneself, Self-Discovery, and Hope}

Exiting homelessness in women can be understood as a journey - a journey through self- discovery and hope. This journey was a consequence of various unacceptable home situations in either childhood or adulthood. These negative home situations resulted in women's loss of hope, loss of the feeling of at-homeness, and loss of confidence in themselves. They became disconnected from themselves and society; they felt 
depersonalized, disaffiliated, and helpless. They set out on this journey to seek a better home experience, to reconnect with themselves and others, and to recover their lost freedom.

Participants' shared understandings of home conformed to societal ideals of nurturance, safety, and groundedness. Having a home and feeling at home wherever one finds oneself is a very important aspect of adjusting to one's external environment, because home is an ideological construct created through people's histories and lived experiences within their environments. This reality was not lost in the stories told by participants as they explained the consequences they suffered when their life circumstances at home became unsafe and did not measure up to this idealistic expectation of home, and what home signified in their lives.

Difficult and "negative family situations" as well as histories of "physical, sexual, and emotional abuse" (Braitstein et al., 2003, p. 562), which were all triggers for participants, are significant factors contributing to homelessness and the ability to sustain meaningful adult relationships. These findings support Jackson-Wilson and Borgers's (1993, p. 362) idea of "dissociation," which results from family instability in childhood and abuse. Anderson and Rayens (2004) have linked childhood experiences with the development and maintenance of adult relationships, and suggest that the latter is in part dependent on the former:

The effect of one's family of origin, the primary family in childhood, is deeply ingrained in life-long behavior and plays an important role in one's current life situation.... Individuals who were neglected by their parents or who suffered physical abuse during childhood have higher likelihood of becoming homeless. (p. 13)

Women experiencing homelessness are likely to have been abused as children and battered as adults (Toohey et al., 2004, p. 8). According to Anderson and Rayens (2004), "many women become homeless because of violence experienced in a current relationship" (p. 13). Although abuse alone is not a predictor of homelessness, "childhood histories of abuse, and subsequent life time patterns of abuse may lead to the inability to form and maintain adult relationships - which is a predictor of homelessness" (p. 13). According to Golden (1992), the issue is not that these women cannot maintain relationships, but "rather they are unable to carry on when these were lost" (p. 20).

Descriptions of untreated mental illness and addiction as triggers to losing oneself and becoming homeless were common among participants. Lana admitted that she suffered from bipolar and personality disorders, and because of lack of treatment, she got asked to vacate where she lived. Maria said that she had an addictive personality, which she attributed to difficulties in her childhood. She suffered neglect and abuse as a child and was diagnosed with depression very early in life.

Swenson (1998) wrote that home "signifies the rootedness at the centre of people's lives" and the centre of "reach" to the outside world (p. 384). Home is understood to mean "safety, freedom, and a location of refuge and familiarity" (Drevdahl, 2002, p. 4). Its loss both in the emotional and in the physical sense, as seen in these women, led to confusion, loss of identity, and intense loneliness. Drevdahl (2002) challenged the notion that home is always a place of safety and comfort, suggesting that it might represent the centre of disequilibrium for those who are abused. As seen in the lives of these women, their home lives were full of confusion, fraught with struggles and insecurity. When they lost the sense of belonging that home was supposed to manifest in their lives, they felt defeated and alone. The loss these women experienced at home affected their feelings toward themselves and their personal identities, resulting in feelings of detachment and loneliness. 
Personal detachment assumes disunity between the self and the environment, with consequent feelings of loss and confusion (Osuji, 2012). According to Dovey (1985), home refers to the "intersubjective relationship that brings the self into being" (p. 62), and as such becomes fundamental to people's identities. This interpretation presupposes that home plays a major role in individual identity and the sustenance of a grounded sense of self, and when the feeling of at-homeness is lost, there is a sense of detachment from the self.

Dovey (1985) believed home to be a place where individual identity is evoked through connections to the past and identification with a home; these connections enable individuals to "establish who they are and where they come from" (p. 36). Self-identity according to this point of view refers to the unique ways individuals distinguish themselves from all others. As a result, women experiencing homelessness express feelings of depersonalization and stigmatization that have detrimental effects on their personhood. As one of the most significant places that contribute to individual identity, "the place individuals call home invariably shapes them," and can influence their everyday choices that "unfold their entire life stories" (Proshansky, Fabian, \& Kaminoff, 1983, p. 59).

Feelings of personal detachment and vulnerability, heralded by the experience of homelessness, led to personal exclusions from the community and the self, as if participants had no control over their actions as a result of feelings of uncertainty regarding their identities. Ekman, Skott, and Norberg (2001, p. 61) wrote, "The essence of place does not deal as much with the geographical place and how it looks, as with a place to which one either belongs [insiders] or does not belong [outsiders]." There was consensus among participants on the understanding of home; they saw home not in terms of the physical structure of a house, but in terms of the feelings people have about the place they call home, their environments, and the relationships that they share with others in that space. In the lives of these women, home became a place that played a key role in their feelings of social exclusion. Without a home, participants felt disaffiliated and excluded from their families, their communities, and society.

Participants agreed that homelessness was more about people and less about housing status, and therefore exiting homelessness is not as simple as putting individuals into houses. This is contrary to the contemporary definition of homelessness as a condition of being without a regular dwelling place. For the participants, having a home and feeling at home signified a strong and intimate relationship with their environments, and when this relationship was weakened or broken, they felt disconnected and ostracized, and therefore distanced themselves from support networks. These findings suggest that the singular focus on people's residential status in defining homelessness can be misleading. As Tucker (1994) observed, homelessness is a condition of "absolute lack of self fulfillment or control of one's physical environment, lack of emotional comfort, absence of intellectual stimulation, and a state of utter social loneliness" (p. 184).

Sometimes the women viewed the experience of homelessness - which they considered not a choice but a consequence of their decision to exit inhuman, abusive, and sometimes dangerous home situationsin a positive manner. Some participants implied that they preferred living the homeless life to being in an abusive relationship. According to Sandy, "nothing is worse than living in abusive relationship." As such it did not matter a lot what circumstances they endured while living on the streets, since the alternative was considered more detrimental to their personhood. They explained that although the singular act of leaving home represented for them a period of heightened vulnerabilities, it was also empowering to leave abusive circumstances because it meant taking control of their situations. Sandy said, "I know nobody is going to 
hit me with water anymore. He doesn't even know where I am. I had a big house but no freedom, no home; it feels good to be free [sobbing and fighting back tears]."

Shrinking of available support networks for the homeless reduces the array of material assistance and information that they may access in order to meet their basic needs as well as to identify courses of action toward exiting homelessness (Grigsby et al., 1990). Stein, Dixon, and Nyamathi (2008) argue that the expansion of the support available to homeless women "correlates to a greater self esteem, lesser emotional distress, and more positive coping" (p. 416). Participants considered the support they received while residing at the shelter to be instrumental to their renewed hopefulness about their abilities to exit homelessness. These social supports were developed through mingling with others, accessing counselling and treatment programs, and participating in group activities.

The beneficial effects of social supports are due to their buffering properties in the presence of stress. Supportive encounters may come in the form of attachments available, frequency of interactions with others, or even the mere perception of possible support. This journey out of homelessness was considered a stressful life event for participants, but formal and informal contact with people enhanced their coping capabilities. Tara stated, "It's how I feel about myself inside, because whether it is through the pastor, through the scriptures, through the counsellors or through the women on the floor, older or younger ... you make lots of friends and they are supportive." Supportive encounters enabled these women to set realistic goals for themselves and work toward achieving them. Dalton and Packenham (2002, p. 82) observed that socialization and reliance on others encourages homeless people to seek professional help, which in turn improves their coping strategies and ability to achieve self-defined goals.

\section{Implications for Practice and Recommendations}

Support workers are involved in the care of women experiencing homelessness at different trajectories in and out of homelessness. Therefore, they are in optimal positions to take leadership roles in assisting women to exit the homeless situation. Before this can be done successfully, service providers need to question the manner in which homelessness is conceptualized and defined. The focus on defining homelessness in relation to the residential status of clients supports an attitude that implies that individuals who live at home cannot be homeless at the same time. Findings in this study suggest otherwise; it is when the feelings of homelessness at home are not adequately addressed that women end up on the streets.

The recognition that "women's stories are texts that can be interpreted" (Leight, 2002, p. 108) contributes to practice knowledge, and as demonstrated by the stories of the women who participated in this research, such stories can be a powerful vehicle for communication and change. This study demonstrates that there are commonalities in how women without children experience and exit homelessness, but it also underscores the uniqueness of each story. Service providers need to listen to each individual story and provide appropriate assistance. They also need to build bridges with interdisciplinary groups, through advocacy and education, to close the gap created by societal attitudes toward women and domestic violence victims (Osuji, 2012). Although identification of abuse might be difficult, it underscores the need to follow up with at-risk women at regular intervals. By building rapport with clients, support workers will be in an optimal position to recognize and prevent abuse before it becomes entrenched. 
Those assisting individuals experiencing homelessness in whatever capacity need to connect them to services, help them to dream again, enable them to set realistic personal goals, and encourage them to work toward the achievement of these goals. Education of society at large about stigmatization of the homeless is a joint responsibility of service providers and policy makers. Eradicating homelessness is not just about finding housing; rather, it is also about enabling homeless women to rediscover themselves and rebuild their hopes for a better tomorrow.

Support workers must build trust with this population, through being part of their lives, developing connections with them, and bringing services to them. Active listening, and being educated about what circumstances put women on the journey to exit homelessness, will enable staff to understand what life on the streets is like.

\section{CONCLUSION}

It is only through interpretation that human beings appreciate and understand their environments and social phenomena. Homelessness as a human experience is different from having no fixed address; it may also mean isolation, disengagement, and loss within a society that is immersed in wealth and ownership of property. Exit from homelessness therefore could mean different things to different people; it could represent the search for a better home, the search for oneself, or a journey into the unknown. Listening to the stories of women who are experiencing homelessness will lead to increased awareness and understanding of their experiences and may help to inform practice and influence design of services that are aimed to assist them.

The meaning of the experience of exiting homelessness is that of a journey through losing oneself, selfdiscovery, and hope. The women embarked on this journey because of various unacceptable home situations in their past histories. These negative circumstances resulted in their loss of hope, loss of the feeling of athomeness, and loss of confidence in themselves. They subsequently became disconnected from themselves and society at large; they felt depersonalized and helpless. Exiting homelessness is about finding oneself. The journey out of homelessness involves literal movement out of previous home situations, and figurative passage through time and within the self to seek personal authenticity.

Support workers and supportive interventions make a difference in the lives of individuals, groups, or populations. The meaning of exiting homelessness among women without children as explored in this study is a dynamic interplay among rich themes and subthemes that, when interpreted, weave a textual tapestry that opens up for more questioning, more reflection, and greater understanding of the experience. Findings from this study, we hope, will enrich the understanding of the obstacles women face as they navigate, strategize, and cope through their journeys out of homelessness. It is necessary that service providers and policy makers use this information to identify issues and design programs to enable women without children to exit the homelessness situation.

Supportive care to the homeless should occur wherever and whenever services are needed. It is important for case workers to focus on the goals these women have set for themselves, offer them assistance, provide material support to enable them to reconnect with themselves, and nurture self-discovery. "All who work with the homeless must be in the vocation to be more human, to ask rather than assume, to listen rather than direct, and to respect rather than judge" (Koch, Lewis, \& Quinones, 1998, p. 82). 


\section{REFERENCES}

Anderson, D., \& Rayens, M. (2004). Factors influencing homelessness in women. Public Health Nursing, 21(1), 12-23. Bahr, H., \& Caplan, T. (1974). Old men drunk and sober. New York: New York University Press.

Braitstein, P., Li, K., Tyndall, M., Spittal, P., O’Shaughnessy, M., Schilder, A., Johnston, C., .. Schechter, M. (2003). Sexual violence among a cohort of injection drug users. Social Science and Medicine, 57, 561-569.

Calgary Homeless Foundation. (2011). Facts on homelessness in Calgary. Retrieved November 3, 2011, from http:// calgaryhomeless.com/assets/get-involved/FactsheetJan2011.pdf

Calgary Homeless Foundation. (2012). Point-in-time count report. Retrieved September 4, 2012, from http://calgary homeless.com/assets/research/Winter2012-PIT-Final-Report.pdf

Coates, J., \& Mckenzie-Mohr, S. (2012). Out of the frying pan, into the fire: Trauma in the lives of homeless youth prior to and during homelessness. Journal of Sociology and Social Welfare, 37(4), 65-96.

Cohen, M. Z., Kahn, D. L., \& Steeves, R. H. (2000). Hermeneutic phenomenology research: A practical guide for nurse researchers. Thousand Oaks, CA: Sage.

Crist, J. D., \& Tanner, C. A. (2003). Interpretation/analysis methods in hermeneutic interpretive phenomenology. Nursing Research, 52, 202-205.

Cronley, C. (2010). Unraveling the social construction of homelessness. Journal of Human Behaviour in the Social Environment, 20(2), 319-313.

Dalton, M., \& Packenham, K. (2002). Adjustment of homeless adolescents to a crisis shelter: Application of a stress and coping model. Journal of Youth and Adolescents, 31, 79-89.

Dovey, K. (1985). Home and homelessness. In I. Altman \& C. M. Werner (Eds.), Home environment (pp. 33-64). New York: Plenum Press.

Drevdahl, D. (2002). Home and border: The contradictions of community. Advanced Nursing Science, 24(3), 8-20.

Ekman, I., Skott, C., \& Norberg, A. (2001). A place of one's own. The meaning of lived experience as narrated by an elderly woman with severe heart failure: A case study. Scandinavian Journal of Caring Sciences, 15(1), 60-65.

Evans, R., \& Forsyth, C. (2004). Risk factors, endurance of victimization, and survival strategies: The impact of the structural location of men and women on their experiences within homeless milieus. Sociological Spectrum, 24(4), 479-505.

Fleming, V., Gaidys, U., \& Robb, Y. (2003). Hermeneutic research in nursing: Developing a Gadamerian-based research method. Nursing Inquiry, 10, 113-120.

Fontana, A., \& Frey, J. (2000). The interview: From structured questions to negotiated text. In N. K. Lincoln and Y. S. Lincoln (Eds.), Handbook of qualitative research ( $2^{\text {nd }}$ ed., pp. 645-672). Thousand Oaks, CA: Sage.

Fry, P. S., \& Barker, L. A. (2002). Quality of relationships and structural properties of social support networks of female survivors of abuse. Quality, Social and General Psychology Monographs, 128(2), 139-163.

Gadamer, H. (2004). Truth and method. New York: Continuum. First published 1960.

Gamache, G., Rosenheck, R., \& Tessler, R. (2003). Overrepresentation of women veterans among homeless women. American Journal of Public Health, 93, 1132-1136.

Golden, S. (1992). The women outside: Meanings and myths of homelessness. Berkeley, CA: University of California Press.

Graham, J. R., \& Schiff, J. W. (2010). Introduction to the special issue: Homelessness in Canada. Journal of Sociology and Social Welfare, 37(4), 9-11.

Grigsby, C., Baumann, D., Gregorich, S. E., \& Roberts-Gray, C. (1990). Disaffiliation to entrenchment: A model for understanding homelessness. Journal of Social Issues, 46(4), 141-156.

Hwang, S. (2002). Homelessness and health. Canadian Medical Association Journal, 164(2), 229-233.

Jackson-Wilson, A., \& Borgers, S. (1993). Disaffiliation revisited: A comparison of homeless and non-homeless women's perceptions of family of origin and social supports. Sex Roles, 28, 361-377.

Jardine, D. (1990). Awakening from Descartes' nightmare: On the love of ambiguity in phenomenological approaches to education. Studies in Philosophy and Education, 10, 211-232.

Koch, R., Lewis, M., \& Quinones, W. (1998). Homeless: Mothering at rock bottom. In C. G. Coll, J. L. Surrey, \& K. Weingerten (Eds.), Mothering against all odds: Diverse voices of contemporary mothers (pp. 61-84). New York: Guilford Press. 
Leight, S. B. (2002). Starry night: Using theory to inform aesthetic knowing in women's health nursing. Journal of Advanced Nursing, 37, 108-114.

Lenon, S. (2000). Living on the edge: Women, poverty, and homelessness in Canada. Canadian Women Studies, 20, 123-126.

Makiwane, M., Tamasane, T., \& Schneider, M. (2010). Homeless individuals, families and communities: The societal origins of homelessness. Development Southern Africa, 27(1), 39-49.

Metraux, S., \& Culhane, D. P. (1999). Family dynamics, housing and recurring homelessness among women in New York City homeless shelters. Journal of Family Issues, 20(3), 371-396.

Milburn, N., \& D' Ercole, A. (1991). Homeless women: Moving towards a comprehensive model. American Psychologist, 46, 1161-1169.

Millburn, G., Rotheran-Borus, M., Rice, E., Mallet, S., \& Rosenthal, D. (2006). Cross-national variations in behavioural profiles among homeless youth. American Journal of Community Psychology, 37(1/2), 63-76.

Miller, K., \& DuMont, J. (2000). Countless abused women: Homeless and inadequately housed. Canadian Women Studies, 20, 115-122.

Moules, N. (2002). Hermeneutic inquiry: Paying heed to history and Hermes - An ancestral, substantive and methodological tale. International Journal of Qualitative Methods, 1(3), 1-40.

Munhall, P. L. (2001). Nursing research: A qualitative perspective (3rd ed). Sudbury, MA: National League of Nursing.

National Working Group on Women and Housing. (2006). Women and girls: Homelessness and poverty in Canada. Retrieved September 4, 2012, from http://www.equalityrights.org/when/resources_pdfs/factsheet06-e.pdf

Nyamathi, A. (2008). Effects of psychosocial and situational variables on substance abuse among homeless adults. Journal of the Society of Psychologists in Addictive Behaviours, 22, 410-416.

Olufemi, O. (2000). Feminization of poverty among street homeless women in South Africa. Development Southern Africa, 17, 221-234.

Osuji, J. C. (2012). Single women and the journey to exit homelessness: A hermeneutic inquiry. Berlin: Lambert Academic Publishing.

Ploeg, J., Hayward, L., Woodward, C., \& Johnston, R. (2008). A case study of a Canadian homelessness intervention program for elderly people. Health and Social Care in the Community, 16(6), 593-605.

Proshansky, H., Fabian, A., \& Kaminoff, R. (1983). Place identity: Physical world socialization of the self. Journal of Environmental Psychology, 3, 57-83.

Richter, S., \& Chaw-Kant, J. (2010). Canadian homeless women: Gaps in the research agenda. International Journal of Child Health and Human Development, 3(1), 7-15.

Rogers, T., \& Marshall, E. (2012). On the road: Examining self-representation and discourse of homelessness on young adult texts. Journal of Adolescent and Adult Literacy, 55(8), 725-733.

Ruttan, R., Laboucan-Benson, P., \& Munro, B. (2012). Does a baby help young women transition out of homelessness? Motivation, coping and parenting. Journal of Family Social Work, 15(1), 34-49.

Shephard, S., Low, H., \& Meisner, A. (2003). The 2003 Toronto report card on housing and homelessness. Toronto. Retrieved April 5, 2012, from http://www.toronto.ca/homelessness/pdf/reportcard2003.pdf

Stein, J., Dixon, E., \& Nyamathi, A. (2008). Effects of psychosocial and situational variables on substance abuse among homeless adults. Journal of the Society of Psychologists in Addictive Behaviours, 22, 410-416.

Streubert-Speziale, H., \& Rinaldi-Carpenter, D. (2007). Qualitative research in nursing: Advancing the humanistic imperative $\left(4^{\text {th }}\right.$ ed). Philadelphia: Lippincott Williams \& Wilkins.

Swenson, M. (1998). The meaning of home to five elderly women. Health Care for Women International, 19, 381-393.

Tischler, V. A., \& Vostanis, P. (2007). Homeless mothers: Is there a relationship between coping strategies, mental health and goal achievement? Journal of Community and Applied Social Psychology, 17(2), 85-102.

Toohey, S., Shinn, M., \& Weitzman, B. (2004). Social networks and homelessness among women heads of household. American Journal of Community Psychology, 33(1), 7-20.

Tucker, A. (1994). In search of home. Journal of Applied Philosophy, 11, 181-187.

Woodward, J., Eberle, M., \& Kraus, D. (2002). Research project on homelessness in Greater Vancouver. Vancouver: Greater Vancouver Regional District. 